\title{
Corrupción y regeneración: Víctor Andrés Belaunde y «La crisis presente»
}

por

Martín Santiváñez Vivanco*

Universidad Privada San Ignacio de Loyola, Perú

\begin{abstract}
Víctor Andrés Belaunde, uno de los pensadores más relevantes del arielismo latinoamericano, sostuvo la necesidad de combinar el diseño institucional con una regeneración valorativa como remedio a la crisis política que atravesaba el Perú. Así, la combinación de diseño institucional y vitalismo axiológico configuró un enfoque sintético que introdujo en la discusión pública una visión de desarrollo integral en el que la lucha contra la corrupción y los problemas institucionales podian ser abordados, de manera complementaria, desde una perspectiva ética. Tal dimensión servía para fortalecer la construcción de un Estado inclusivo, uno de los objetivos políticos de la generación arielista.

Palabras Clave: corrupción; regeneración; Victor Andrés Belaunde; arielismo; La crisis presente.
\end{abstract}

\section{ANTECEDENTES}

Si las instituciones son la clave para comprender el cambio histórico, la propia historia es una poderosa herramienta para el análisis institucional del fenómeno de la corrupción ${ }^{1}$. La historia permite dilucidar el iter estructural y dinámico de un fenómeno profundamente arraigado en las sociedades latinas $^{2}$, que debe ser abordado de manera multidimensional ${ }^{3}$. La

* Fellow del Navarra Center for International Development de la Universidad de Navarra, miembro correspondiente por el Perú de la Real Academia de Ciencias Morales y Políticas de España y numerario de la Academia Peruana de Ciencias Políticas.

1 Noonan, 1987. North, 1990. Bardham, 35/3 (Pittsburgh, 1997).

2 Levi y Nelken, 1996. Little y Posada Carbó, 1996.

3 Doig y McIvor, 20/3 (Londres, 1999). Von Alemann, 42 (2004). 
forma en que la corrupción afecta a los países en desarrollo, ya sea en el marco estatal de las democracias de calidad ${ }^{4}$ o en el que configuran los autoritarismos competitivos ${ }^{5}$, está determinada por una serie de variables que interactúan en diversos planos institucionales, formales e informales ${ }^{6}$. A pesar del dinamismo sistémico propio de nuestra época y del carácter esencialmente mutable de la corrupción en su dimensión histórica ${ }^{7}$, es posible establecer ciertas características comunes que permiten delinear algunas estrategias de lucha anti-corrupción basadas no sólo en los incentivos formales, sino también en el conocimiento específico de la cultura política de los países en desarrollo ${ }^{8}$, esto es, en el análisis de los valores y principios que configuran una tradición histórica determinada, lo que, por fuerza, nos conduce a una mirada funcional de las instituciones informales ${ }^{9}$.

Como es sabido, la corrupción influye de manera directa en la pobreza, la informalidad, la mala salud, la baja esperanza de vida y la distribución desigual de los ingresos y la riqueza ${ }^{10}$. El carácter negativo de estos factores configura un mal endémico regional, una especie de trampa latinoamericana de la corrupción ${ }^{11}$, lo que origina una serie de paradojas institucionales que ralentizan las reformas políticas, minando la construcción de un sector privado eficaz e inclusivo ${ }^{12}$. La tensión relacional provocada por estas paradojas, a la postre disfuncionales, se agrava ante el diseño voluntarista de enfoques excluyentes y apriorísticos en el estudio del fenómeno de la corrupción. La aplicación de políticas de transparencia y la consecución de un modelo de

4 Diamond, 2008.

5 Levitsky y Way, 2010.

6 Williamson, 1985. Hill, 31 (2003).

7 Choi y Thum, 46/3 (2005).

8 Diamond, 1994.

9 Putnam, 2003. Lipset y Lenz, 2000. Treisman, 76 (2000). Además, son importantes los trabajos que asumen este enfoque culturalista (con frecuencia histórico-político) y que analizan la dimensión cultural-valorativa sin restar importancia a la aproximación económica del interés individual o a la teoría del rational choice que prima en la literatura de ciencia política. Entre los culturalistas destacan, Harrison, 1985; 1992; 2000. Moynihan, 1993. Putnam, 2000; 2002; 2003; 2010. Lipset, 1987; 2000. Sowell, 1987. Desde una perspectiva esencialmente normativa, los arielistas peruanos se adelantaron a su época sosteniendo la importancia de una política basada en el principio de realidad aplicado al espacio-tiempo histórico. 2001.

10 Ades y di Tella, 45 (1997). Kaufmann, 107 (Washington). Rose-Ackerman, 2001. Jain,

11 Collier, 2008.

12 Klitgaard, 1991: 8. 
high performance government colisionan con la aproximación unidimensional que prima en algunos entornos analíticos ${ }^{13}$.

Por ello, sin abandonar otros enfoques y con ánimo de enriquecer la dimensión teórico-normativa, el empleo del método histórico-crítico, permite dilucidar ciertas aristas del subdesarrollo recordando a los responsables de las políticas públicas que la corrupción está estrechamente vinculada a las instituciones informales (tradiciones, costumbres, valores, etc.) en beneficio de unos pocos y en detrimento del bien común ${ }^{14}$. Siendo así, una estrategia global de lucha contra el fenómeno de la corrupción ha de tomar en cuenta el factor cultural que influye en la configuración social, particularmente, en las relaciones intra-élite, sujetas a un marco valorativo específico. Además, siempre en este contexto de pluralismo analítico, es preciso resaltar la importancia de la dimensión ética en la configuración de las complejas redes que promueven la corrupción ${ }^{15}$, así como la manera en que éstas interactúan de manera fáctica con la estructura institucional, determinando la calidad del gobierno, dotando de racionalidad al Estado, en el marco de una región con profundas desigualdades, como es el caso de Latinoamérica ${ }^{16}$.

En efecto, la corrupción forma parte de la realidad latinoamericana, ya sea en calidad de legado institucional moldeado por incentivos ${ }^{17}$ o en su vertiente de cultura cívica, capaz de modificar las relaciones de confianza y reciprocidad en la esfera público-privada. En este sentido, repensar el diagnóstico y el programa de acción defendido políticamente por el novecientos latino implica, a la vez, revalorizar su diseño estratégico para el fortalecimiento de las instituciones democráticas. Este fortalecimiento, según el arielismo continental, se encontraba ligado a la regeneración de unas instituciones formales alimentadas por los frenos y contrapesos de un marco valorativo capaz de promover reformas efectivas de prevención y control en el ámbito nacional, sectorial y organizacional. De alguna manera, el arielismo se adelantó prospectivamente a los usos y limitaciones del contexto analítico de su época al defender la incorporación de la idiosincrasia del entorno local al diseño institucional del ejercicio del poder, un extremo que hoy, habitualmente, se sostiene en la literatura ${ }^{18}$.

13 Klitgaard y Light, 2005: 4-7.

14 Quiroz, 2008. Levitsky, 2006. Sobre el bien común en el ámbito del desarrollo, véase, por ejemplo, Melé y Castellà, 2010.

15 Heywood, 1997.

16 Shleifer y Vishny, 108/3 (Oxford, 1993). Brinkerhoff, 20 (2000).

17 Tanaka, 2005. Weyland, 9/2 (1998).

18 Fritzen, 24/3 (Singapur, 2006). Rothstein, 2011. 
De esta forma, para el novecentismo arielista, la estrategia anticorrupción (y por extensión, el diseño integral del Estado) debía tener en cuenta, a la par que los incentivos formales propios de los gobiernos sujetos a la democracia representativa, la existencia de instituciones informales capaces de modelar la interacción humana estructurando las relaciones de poder (civic culture). Así, de manera sintética, fruto de su adhesión al idealismo y al intuicionismo bergsoniano, los arielistas peruanos buscaron la fusión equilibrada del positivismo con la dimensión normativa, defendiendo la necesidad de aprovechar la herencia de las instituciones informales (path dependence) desarrolladas paulatinamente a través de la historia ${ }^{19}$, transformándolas en auténticos marcos de referencia en el proceso de configurar espacios públicos de poder, escenarios concretos en los que se expande el fenómeno endémico de la corrupción latina ${ }^{20}$.

\section{CORRUPCIÓN Y ARIELISMO}

El Perú no es un país ajeno a la tendencia regional que sitúa a la corrupción como un problema fundamental de los procesos políticos latinos ${ }^{21}$. La importancia de la corrupción en el marco institucional peruano ha sido decisiva y fue denunciada por individuos concretos y diversas generaciones socio-políticas ${ }^{22}$. Una de esas generaciones, acaso la más articulada en el ámbito intelectual, fue la del novecientos, también conocida como la generación arielista $^{23}$. En efecto, el voluntarismo reformista del arielismo latino fue sumamente crítico con la corrupción focalizada en el Estado, denunciando sus

19 Almond y Verba, 1965. North, Wallis y Weingast, 2009. Johnston, 2010.

20 La corrupción persiste en la esfera pública desde las independencias y se presenta como un proceso, aunque no sistémico, sí ampliamente extendido. Sobre el particular, véase Little y Posada-Carbó, 1996: 10. En cuanto a los rasgos que se precisan para que un nivel de corrupción se considere sistémico, véase Vanucci, 1/2 (2009): 245.

21 Vargas Haya, 2005.

22 Desde el individualismo radical, el pensador anarco-positivista Gonzales Prada, 1976: 107, lo sostuvo gráficamente con una frase que ha pasado al imaginario colectivo del país: «En resumen, hoy el Perú es un organismo enfermo: donde se aplica el dedo brota pus».

23 Véase Loayza, 1990. También Planas, 1994, 23-28, ambos para ahondar en la distinción entre el novecentismo y el arielismo peruano, destacando el caso concreto de José de la Riva Agüero, un novecentista contrario al idealismo rodosiano, y partidario, por formación histórica y voluntad de poder, del posibilismo integrador, suerte de «bloquismo sudamericano». Siempre con matices, véase la carta de Riva Agüero a Sánchez de 24 de agosto de 1920 (Sánchez, 1985), en la que el líder novecentista afirma que no se somete a «un americano hueco y pueril». 
posibles causas y sugiriendo remedios mixtos, institucionales y éticos. Llamados así por su identificación con Ariel, el libro del uruguayo José Enrique Rodó (1871-1917), los arielistas renovaron el discurso público de su tiempo, apelando al idealismo, al compromiso con la política de sus países y al retorno al nacionalismo programático, reivindicando la historia particular de cada pueblo americano. Rodó tomó la figura de Ariel del romance tardío shakesperiano La tempestad (1611). El personaje simboliza el imperio de la razón, la generosidad continental, la raíz espiritual de la civilización y la victoria final sobre Calibán, encarnación suprema de la sensualidad y el materialis$\mathrm{mo}^{24}$. El Ariel de Rodó propuso a la juventud del continente el retorno a la disciplina propia de una clase dirigente (virtus), promoviendo una identidad hispanoamericana en oposición al creciente poderío de los Estados Unidos en la región. Esta especie de esencialismo latino a manera de dique idealista buscó frenar el expansionismo económico anglosajón y los espasmos del utilitarismo fomentados por la disciplina del positivismo decimonónico ${ }^{25}$.

Los novecentistas sostuvieron que el triunfo final del idealismo traería consigo «el orden en la vida, la noble inspiración en el pensamiento, el interés en la moral, el heroísmo en la acción y la delicadeza en las costumbres» ${ }^{26}$. La corrupción, en este sentido, estaba vinculada a la decadencia materialista de la civilización utilitaria propia del orbe anglosajón. Era un sub-producto, una extensión impuesta por el expansionismo de Calibán. Como remedio, el arielismo propuso una solución mixta que otorgaba a la reforma institucional el apoyo eficaz de una regeneración valorativa. La apuesta por un idealismo panamericano capaz de plasmarse en la construcción de instituciones eficientes, configuraba una ruptura frontal con el clima positivista que dominaba la academia y la administración pública. El cambio de paradigma implicaba, antes que el abandono total del positivismo metodológico, un enfoque más complejo, vinculado al móvil de retorno nacionalista que caracterizó al novecientos.

Este anhelo de reforma basado en un idealismo con aspiraciones pragmáticas pronto tuvo que enfrentarse al bloqueo de la clase política y a los propios lastres institucionales de un Estado sesgado por privilegios mercantilistas e híper-centralistas, generadores de islas de corrupción. Así lo señaló José de la

24 En Rodó, 1967: 246, se interpela a la juventud continental en virtud de un compromiso con el futuro: "Consagrad una parte de vuestra alma al porvenir desconocido».

25 Sobre la vida de Rodó, véase Gascó Contell, 1970. Para un estudio crítico sobre su impronta véase la imprescindible obra analítica de Torrano, 1973. Sobre la implantación del positivismo en el Perú, con reticencias sobre la interpretación, Quintanilla, 2004: 43-79.

26 Rodó, 1967: 207. 
Riva Agüero, el genio precoz ${ }^{27}$ que criticó el sueño de Rodó con estas frases lapidarias:

Algunos, optimistas simpáticos, pero también incorregibles soñadores, creen (y ojala estuvieran en lo cierto) que las repúblicas hispanoamericanas no necesitan entregarse casi exclusivamente a la actividad industrial y mercantil; que deben reservar una buena parte de su espíritu para la idealidad [...] El representante más ilustre de esta escuela es un sagaz crítico uruguayo, estilista exquisito, finísimo orfebre de la prosa, José Enrique Rodó. Los consejos y las exhortaciones que contiene su encantador folleto Ariel, son excelentes para predicados en Europa o en la América sajona; pero ¡qué peregrina ocurrencia la de dirigirlos a los latinoamericanos 28 !

La intuición de Riva Agüero actuaría en su contra. El idealismo arielista se mostraría incapaz de interpretar un nuevo factor esencial de la realidad novecentista: la irrupción de las masas en la ecuación del poder ${ }^{29}$. Este fenómeno alteraría por completo el sistema de partidos, la configuración electoral, el espectro ideológico y la calidad y tipología del liderazgo. La política de masas post-arielista transformaría las relaciones de patronazgo, reconfigurando las redes clientelares, los factores causales de vinculación política y los niveles de representación. Todo ello generó, a su vez, nuevos escenarios y actores en el ámbito de la corrupción ${ }^{30}$.

27 A los veinte años debutó en las letras recibiendo los elogios encendidos de Unamuno y la aprobación de Menéndez Pelayo. Véase Sánchez, 1985: 13. Unamuno lo llamó «espíritu sereno, valiente, culto». Sobre el particular, el epistolario Riva Agüero-Unamuno, recogido en Pacheco Vélez, 1993: 186-222.

28 Véase Zaldumbide, 1951: 67, quién atinó al describir el ideal unionista y ecléctico del uruguayo Rodó desvinculado del cristianismo tradicional, y pleno de matices heterodoxos: «Quiso fraternizar no solo en Cristo, sino también en Renán».

29 Aunque ningún arielista peruano actuó a manera de laudator temporis acti o prophète su passé, si hay páginas en las que el arielismo refleja un paternalismo positivo. Así, el pueblo, in statu pupillari, debía ser educado por una minoría selecta de intelectuales comprometidos con la reforma del Estado, a manera de vanguardia modernizadora, creando canales y procesos de movilidad. No era una visión radicalmente estática, pero sí le otorgaba un rol preponderante a las elites como agentes de transformación social. Con el tiempo, el desborde popular liquidaría esta tendencia elitista. Véase, Matos Mar, 2004: 129-131. Sobre el ideal aristocrático e intelectual del líder político de su generación, véase De la Riva Agüero, 1975: 33: «Quienes vengan con nosotros, deben ser dignos de nosotros. Al rebaño venal, no lo necesitamos ni aceptamos». Sobre el elitismo liberal de los novecentistas véase, por todos, Neira, 2005: 366. Al hablar de ideal elitista nos referimos, por supuesto, a un elitismo del espíritu, no el de índole crematístico. Por eso, García Calderón, 1949: 20, el tercer arielista, defendió el carácter demófilo del movimiento, contrario, sin embargo, a la adulación populista.

30 Vargas Haya, 2005. 
La estrategia arielista de aproximación multidimensional a los intentos de reforma del Estado -superadora de la ingeniería radicalmente comtiana- también estuvo caracterizada por su mayor eclecticismo y, a la par, por la adhesión manifiesta al pragmatismo de cuño nacionalista. Era tan poderosa la invocación al estudio de la realidad nacional que sus sucesores políticos e intelectuales, los miembros de la generación del centenario de la independencia, la hicieron suya aunque, en el camino, eliminaron y combatieron la herencia arielista $^{31}$. El parricidio de los arielistas a manos del «Conversatorio» ${ }^{32}$ no destruyó el contiuum político de introspección nacionalista. El surgimiento de los partidos de masas y la emergencia plebeya ${ }^{33}$ que posteriormente devendría en un movimiento caracterizado por el desborde popular y la crisis del Estado, profundizaron la autocrítica basada en la psicología social. La actitud nacionalista se mantuvo, plasmándose en un análisis condicionado por una renovada metodología marxista que reivindicó para sí el paradigma científico. El positivismo abonó el terreno para las cosmovisiones totalizadoras que apelaban al modelo conductista y, bajo esta premisa, el arielismo arielista sería tildado de «pasadista» y «colonialista» ${ }^{34}$.

Con todo, la influencia de Ariel, a principios del siglo XX, uno de los libros más glosados en toda Hispanoamérica, fue innegable. Sus escoliastas pertenecieron a diversas escuelas y la impronta de Rodó se prolongó de manera real, pese a la proscripción política que pesaba sobre sus primitivos portavoces, debido a su pertenencia al reformismo liberal, estigma calificado como «demo-burgués» ${ }^{35}$. Así, la generación del Centenario, marco fundacional de la izquierda moderna en el Perú, bajo el liderazgo de Víctor Raúl Haya de la Torre (1895-1979) y José Carlos Mariategui (1895-1930), bebió de fuentes arielistas, pero al proclamarse marxista, rechazó a sus predecesores liberales y condenó a sus figuras más importantes a una suerte de damnatio memoriae. Años después, aunque el encono ideológico persistía la derrota política del arielismo generacional permitió una lectura hasta cierto punto positiva sobre la herencia de los novecentistas, tanto desde las izquierdas como de posiciones social cristianas, conservadoras y liberales.

31 Sánchez, 1968.

32 También fueron conocidos como «la generación del Conversatorio» por las reuniones, en clave universitaria, en las que se planteaban diversos problemas de la realidad nacional. Véase Gonzales, 1976: 123-126.

33 Saint Úpery, 32 (Quito, septiembre 2008): 75-87.

34 Mariategui, 1995 [1928]: 199-200.

35 Mariategui, 2005: 444. 
Pese a que la obra estuvo dedicada a toda la juventud americana, Ariel fue leído, principalmente, por las elites universitarias asentadas en las capitales, una intelligentsia en ciernes que buscaba dar el salto a la vida pública ${ }^{36}$. Y precisamente fue en las universidades animadas por el espíritu arielista, dónde se impulsó el estudio de la problemática nacional, fomentándose la movilidad social y la renovación ideológica. De alguna manera, la emergencia de sectores intelectuales afines al marxismo y su posterior configuración en partidos de masas fueron consecuencias directas de la prédica arielista, defensora de una «meritocracia» intelectual por encima de los privilegios económicos. Por último, en el plano externo, el regeneracionismo valorativo del arielismo favoreció un acercamiento de los países latinoamericanos a España, apelando a un renovado concepto de hispanidad y fundando tal aproximación en la tradición común de principios y valores, es decir, en un marco ético concreto. Esta confluencia desembocaría en el fortalecimiento institucional de los lazos iberoamericanos y en la creación de redes de intelectuales y políticos comprometidos con una visión hispanista derivada de la historia y los intereses públicos ${ }^{37}$. Naturalmente, el arielismo, al promover una visión idealista de la política y apostar por el compromiso de la juventud con las labores del gobierno, se opuso al modelo de corrupción institucional que aquejaba al ejecutivo, ya por entonces, una característica notable de nuestros deficientes estados-nación ${ }^{38}$.

\section{BeLAunde, Un ARIELISTA}

La obra de Rodó fue determinante para el pensamiento sintético de Víctor Andrés Belaunde (1883-1966), uno de los líderes del arielismo peruano, integrante, con José de la Riva Agüero y Francisco García Calderón, del triunvirato novecentista ${ }^{39}$. Belaúnde nació en la ciudad de Arequipa, el sábado 15 de

36 Real de Azúa, en la obra de Rodó, 1976: IX, defiende el carácter de sermón laico de Ariel, el mismo que debe relacionarse con las «oraciones rectorales de colación de grados y otras piezas de elocuencia académica que las diversas circunstancias del trámite universitario suelen reclamar». Dicho sermón laico se enmarca dentro de lo que el propio Rodó llamó «literatura de ideas», que permitía exponer el pensamiento social y político de manera literaria. Sobre el particular, véase, García Morales, 1992: 49.

37 Por ejemplo, véase Maíz, 2004: 109, quien afirma que los países hispanoamericanos, desde la independencia, han fomentado diversos intentos de reincorporación cultural a la tradición hispánica. Con todo, es más preciso afirmar que la tradición se mantiene, mediatizada y enriquecida por otros aportes.

38 Quiroz, 2008: 10.

39 La influencia de Rodó en Belaunde fue de primer orden. Véase, Belaunde, 1987, vol. III: 126, dónde sostiene: «De él (Rodó) imitamos la tolerancia y la amplitud, la primacía 
diciembre del año 1883, en una casona ubicada en la calle del Moral, número $316^{40}$. Hijo de Mariano Andrés de Belaunde y de la Torre y de Mercedes Diez Canseco y Vargas, fue el retoño de dos linajes arequipeños que se remontan a la conquista del Perú. Jurista, académico, y filósofo de la cultura, Belaunde sería el protagonista de una dilatada vida intelectual, diplomática y política que culminaría con su elección como presidente de la decimocuarta Asamblea General de las Naciones Unidas en 1959. De los arielistas peruanos sería, sin duda, el que obtuvo mayores triunfos en la carrera pública, de tal forma que su pensamiento se prolongaría, fundamentalmente, a través de dos estructuras políticas, el Partido Popular Cristiano (PPC) y Acción Popular (AP).

Belaunde creció durante los años de la post-guerra con Chile, caracterizada por el resurgimiento material de la sociedad peruana, Belle Epoque que se plasmó, políticamente, en el bipartidismo consolidado (civilismo-pierolismo) y en un lento proceso de introspección intelectual cuyo fin fue dotar al Estado de un proyecto integral de consolidación institucional ${ }^{41}$. Así, el panamericanismo propio del ideal rodosiano (matizado por el realismo escéptico en el plano internacional que Riva Agüero transmitió a sus compañeros de generación) se fusionó ideológicamente con el liberalismo centrista, conformando aquello que Belaunde denominó «patriotismo funcional» ${ }^{42}$, un plan de acción desarrollado de manera consciente con un fin eminentemente práctico: descubrir los problemas y las posibilidades del país, diseñando una estrategia valorativa capaz de transformar la configuración institucional del Estado en función a las necesidades inmediatas de la ciudadanía. De allí, por ejemplo, la identificación del problema del indio, un eje sobre el que giró la polemología política a lo largo del siglo XX, hasta el inicio del terrorismo senderis$\mathrm{ta}^{43}$.

de las perspectivas intelectuales en perpetua renovación, el culto a las formas, su fervor clásico. Los defectos de la orientación de Rodó fueron los nuestros: separación de la cultura y la vida, exagerado estatismo».

40 La biografía más completa sobre Víctor Andrés Belaunde es de su discípulo Pareja Paz Soldán, 1968. También son interesantes los aportes de Klaiber, 1996 y Orrego, 2001. Con todo, la narración más extensa de su vida sigue encontrándose en los dos tomos de sus memorias: Belaunde, 1967a y 1967b. En lo referente a la genealogía y el linaje vasco de los Belaunde, véase el completo estudio de su pariente Rey y Cabieses, 4 (Buenos Aires, 2003). Para diversas semblanzas sobre aspectos puntuales de la vida de Belaunde y su pensamiento, consultar AA. VV., 1963: 437-440, que con ocasión de sus ochenta años le dedicaron sus discípulos.

41 Basadre, 1970, XI: 25-29.

42 Belaunde, 1967b: 457.

43 Véase, por ejemplo, Prieto Celi, 2010: 171-205, sobre la instrumentalización política que del concepto realizó el régimen de Velasco. 
Para ello, el arielismo impulsó el desarrollo de unas ciencias sociales aplicadas a la coyuntura peruana, denunciando la falta de estudios técnicos sobre la realidad de su época, sin dejar de apelar al método positivista y privilegiando la mirada científica bajo el marco de una serie de principios generales, los cuáles, según la óptica arielista, formaban parte de la «psicología nacional», es decir, de la cultura cívica. Por eso, bajo el dominio intelectual del novecientos, verían la luz obras fundacionales de la sociología y la politología sudamericana ${ }^{44}$. En su afán por desligarse de aquello que Belaunde denominó «el vicio del anatopismo» ${ }^{45}$, esto es, la simplificación imitativa de soluciones diseñadas para otros entornos, los arielistas apostaron por aplicar medidas generadas para el espacio-tiempo histórico peruano ${ }^{46}$. El nacionalismo académico y universitario de la generación arielista se convirtió en el caldo de cultivo del posterior indigenismo político de carácter programático-partidista y contribuyó al surgimiento de las diversas izquierdas que, al alcanzar protagonismo, minimizaron la influencia arielista, optando por vincularse intelectualmente al «gonzalez-pradismo» y su discurso reivindicador, a manera de pensamiento proto-revolucionario por excelencia. Sánchez, el gran polígrafo aprista que protagonizó, junto a Mariátegui, la polémica sobre

44 La ciencia política, la historia, la sociología y la literatura recibieron la influencia directa de los libros de José de la Riva Agüero (Carácter de la literatura del Perú independiente, La historia en el Perú, etc.), Francisco García Calderón (El Perú contemporáneo, Las democracias latinas de América, La creación de un continente, etc.) y Víctor Andrés Belaunde (Meditaciones peruanas, La realidad nacional, Peruanidad, etc.). La prosa novecentista renovó el panorama intelectual peruano.

45 Véase García Belaunde y Gonzales, 2007: 107. En la actualidad, la percepción sobre la importación de modelos foráneos es francamente ambivalente. Para un marco analítico sobre el tema, consultar Weyland, 2004. Para una postura favorable, véase Meléndez y Vergara, 2010.

46 El promotor e ideólogo de la teoría del espacio-tiempo histórico fue Víctor Raúl Haya de la Torre (1895-1979), fundador del Partido Aprista Peruano. En el proceso de transformación y modernización programática que ha sufrido el aprismo en las últimas décadas, iniciado durante el periplo vital de Haya, y culminado con Alan García, las ideas arielistas también tuvieron cabida. Planas, 1986: 19-29, sostiene, por ejemplo, que el aprismo se nutrió del neoarielismo de José Ingenieros (1877-1925), Manuel Ugarte (1875-1951), José Vasconcelos (1882-1959) y Alfredo Palacios (1880-1965). Todos ellos profetizaban, como Rodó, una gran cruzada juvenil de unidad continental. Incluso Julio Antonio Mella (1903-1929), presidente de la Federación de Estudiantes de Cuba, dijo de Haya de la Torre que era «el sueño de Rodó hecho carne: es Ariel». De hecho, en 1922 Haya visitó en el Uruguay la tumba de Rodó. Tres años después, en Londres, una de las primeras cosas que hizo fue acudir al sepulcro de Marx. $\mathrm{Su}$ viraje ideológico ya era patente. Véase, sobre este punto, Cossío del Pomar, 1946: 104. Algo parecido ha sucedido con su discípulo Alan García. Véase, sobre su modernización programática, García, 2011. 
el indigenismo, reconoció «la rebeldía general de la promoción de 1920 frente a sus maestros» ${ }^{47}$. Tal rebeldía aceleró la liquidación arielista y el surgimiento de una nueva forma de hacer política.

Pese a este intento de ruptura, la generación del centenario, posterior en el tiempo, no se comprende sin el arielismo. Los arielistas buscaron aproximarse de manera racional al problema de la movilidad social desafiando el hermetismo clasista de la oligarquía del novecientos. Su crítica a las elites -eficiente en su denuncia sobre la desestructuración de la instrucción pública y universitaria- proclamó la necesidad de un Estado de frenos y contrapesos y apostó decididamente por la democracia representativa, la solución del problema del indio y la formación de partidos políticos modernos e inclusivos. Si bien no supo interpretar la virulenta política de masas que surgió después de los procesos revolucionarios globales (cuya génesis, en parte, se debió a la no aplicación de las reformas que los arielistas propusieron) sí señaló con acierto los graves retos sociales a los que se enfrentaba el país de continuar por la senda clasista de excesivos privilegios y formalismos legalistas. De alguna manera, el arielismo peruano sucumbió ante el conjuro de «la maldición de Casandra», ya que predijo la crispación social sin llegar a convertirse en una alternativa política capaz de liderar las transformaciones propias del siglo XX. De hecho, fue en el espectro de la izquierda (aprismo y socialismo) dónde surgieron los movimientos que articularon las reivindicaciones sociales no sólo en modelos ideológicos sino también en organizaciones partidistas eficientes, auténticas máquinas ideológicas ${ }^{48}$ que mutaron por completo el sistema electoral peruano. Sin embargo, el fracaso partidista e institucional del arielismo, fue medianamente compensado por la actuación individual de sus figuras más representativas.

La apuesta consciente de Belaunde por el originalismo político y educativo, a manera de nacionalismo académico, lo condujo al abandono del afán revanchista en el plano militar -defendida por el «gonzalez-pradismo» en el Discurso en el Politeama (1888)- inclinándose por la creación de espacios de influencia regional que equilibrasen el poder de Chile en el cono Sur. Su nacionalismo, en este sentido, fue encauzado hacia la reconstrucción de las instituciones nacionales, es decir, al fortalecimiento de la estructura administrativa del Estado, con especial énfasis en el modelo educativo como canal de transformación social ${ }^{49}$.

\footnotetext{
47 Sánchez, 1968: 9.

48 Alcántara, 2004.

49 Belaunde, 1967b: 622-630.
} 
Para Belaunde y sus compañeros de generación las instituciones estaban diseñadas en función a entornos distintos al de su aplicación práctica. En tal sentido, el apotegma mariateguiano «peruanicemos el Perú», aunque posterior en el tiempo, es de clara impronta arielista. Este nacionalismo inclusivo, antagónico del soberanismo excluyente -Belaunde dedicaría gran parte de sus esfuerzos teórico-políticos a desarrollar el concepto de «peruanidad» en tanto síntesis $^{50}$ - produjo, en la dimensión social, el estudio de las realidades inmediatas (estructuras, procedimientos y clases) y en el plano político, la opción por el centro moderado y el reformismo posibilista, plasmado en la fundación de un partido alejado del establishment civilista, el Partido Nacional Demócrata $^{51}$. Existe, por tanto, no sólo un discurso político arielista sobre la crisis institucional que caracterizó la etapa final de la República Aristocrática ${ }^{52}$. También una acción partidista racionalizada, en gran medida, por la inclinación ideológica de los arielistas (la del liberalismo ilustrado) y su adhesión a los postulados de la democracia representativa y el posibilismo económico. Esta opción que combinaba el diseño institucional basado en el realismo político y la interacción de valores y principios regeneradores de la cultura cívica -con énfasis en la teoría de élites- se articuló en un partido político que fracasó rotundamente en sus incursiones democráticas ${ }^{53}$. También se plasmó en una serie de documentos y libros, muchos de ellos renovadores de las ciencias sociales peruanas y novedosos por su enfoque pluridimensional. Uno de esos escritos, de suma importancia por la repercusión política e intelectual que tuvo en su época y entorno, fue el discurso titulado La crisis presente, epítome del proyecto ético-institucional arielista, pronunciado por Víctor Andrés Belaunde el 13 de julio de 1914, en la apertura del año académico del viejo claustro de San Marcos.

\section{LA CRISIS PRESENTE}

Históricamente, la Universidad de San Marcos ha sido el foro de discusión pública de los grandes problemas nacionales y su relevancia como institución clave de la política peruana se ha mantenido a lo largo de los años ${ }^{54}$. Duran-

50 Entre sus obras peruanistas destacan El Perú antiguo y los modernos sociólogos (1908), La realidad nacional (1931), Meditaciones peruanas (1932), Peruanidad (1942 y 1957). Todas recopiladas en Belaunde 1967a, 1967b, 1987 y 1994.

51 Planas, 1996: 141.

52 Basadre, 1970: XI.

53 Gonzales, 1976: 103.

54 Eguiguren, 1939. 
te las primeras décadas del novecientos, los discursos de apertura sanmarquinos eran ampliamente difundidos entre la clase dirigente del país por estar focalizados en los problemas nacionales de coyuntura. San Marcos era la tribuna más concurrida, no sólo por los miembros de la academia, también por la clase política y las Fuerzas Armadas. Como profesor de filosofía moderna, Belaunde se planteó disertar sobre el idealismo contemporáneo. Sin embargo, fue su amigo arequipeño Juan Manuel Polar quien lo convenció de «tratar con absoluta sinceridad la grave situación por la que atravesaba el país $\rangle^{55}$. El discurso, a la postre, se convirtió en la pieza fundacional del centrismo político peruano del siglo XX porque esbozó un programa distinto al del partido en el poder, inclinándose por el reformismo moderado, sin romper con las reglas de juego de la república aristocrática ${ }^{56}$. En un entorno de crisis institucional y corrupción generalizada el discurso de Belaunde deslindó con el gobierno y propuso reformas institucionales sin romper con el sistema, renunciando a la revolución y al cesarismo burocrático como medios de transformación social.

En tal sentido, Belaunde concibió La crisis presente (1914) desde una postura ideológica de reformismo demo-liberal y con claros afanes académicos y políticos, en plena consonancia con el espíritu reformista que animaba a sus compañeros de generación ${ }^{57}$. Designado para hacerse cargo de la pieza oratoria que daba inicio al año académico, el joven Belaunde tuvo ante sí la

55 Belaunde, 1967b: 465.

56 Belaunde actuó a título personal en la política peruana y endosó apoyos también individuales. Demostró su moderación política cuando intentó ayudar a Víctor Raúl Haya de la Torre a instancias de Ismael Bielich durante el «año de la barbarie» (1933) en el que el aprismo fue perseguido. Aunque la violencia no cesó, como acertadamente señala Martín Belaunde Moreyra: «al menos la iniciativa de Ismael Bielich y Víctor Andrés Belaunde para salvar la vida [de] Víctor Raúl Haya de la Torre se impuso sobre un clima de cainita violencia». Véase Belaunde y García Belaunde, 2009: 131.

57 El discurso de Belaunde fue publicado en los diarios de Lima (El Comercio, 14 y 15 de abril; La Prensa, 14, 15 y 16 de abril; y La Crónica, 14, 15, 16, 17, 18 y 19 de abril de 1914) y luego en la Revista Universitaria (año IX, vol. I, 1914). El acto se llevó a cabo, como era costumbre, en el salón general, bajó la presidencia del vicerrector Lizardo Alzamora, encargado del Rectorado y con la presencia de decanos y catedráticos como Manuel Vicente Villarán, Mariano H. Cornejo, Alejandro Deustua y Felipe Barreda y Laos. A la ceremonia también asistieron los seis miembros de la Junta de Gobierno presidida por el Coronel Oscar R. Benavides. Su nieto Domingo García Belaunde, 2007: 741, afirma que, nombrado para un cargo diplomático en Berlín, Belaunde coordinó en la capital alemana una edición financiada por la Facultad de Letras de la Universidad de San Marcos, de la que alcanzó a corregir pruebas y ver algunos ejemplares. Sin embargo, la edición se perdió por el estallido de la Primera Guerra Mundial. En 1940, Belaunde volvió a publicar el discurso. Finalmente, la edición de 1940, debidamente revisada, fue publicada por Domingo García Belaunde con el 
oportunidad de completar el programa político del arielismo peruano, que finalmente se materializaría en la fundación del Partido Nacional Demócrata (PND), un proyecto liderado por Riva Agüero ${ }^{58}$. La crisis presente buscaba diagnosticar los problemas de la sociedad peruana combinando el análisis académico con diversas reformas de procesos y técnicas gubernamentales, apelando a los sectores modernizadores de la elite y la clase media y presentando a las autoridades del país una nueva dimensión explicativa de la desestructuración institucional. En su discurso, Belaunde intentó conciliar los diversos análisis realizados por sus predecesores en la tribuna sanmarquina, empleando, por primera vez, el método sintético que caracterizaría su pensamiento político. Así, el joven Belaunde sostuvo que la nación peruana atravesaba una grave crisis política, económica y social, una crisis institucional y estructural pero, también, una crisis moral, ética, apelando a los valores como instrumento epistemológico para comprender el subdesarrollo y la corrupción de ese «grande y amado enfermo que se llama el Perú» ${ }^{59}$.

De esta manera, la matriz cultural-valorativa se convirtió en la base de las reformas políticas que Belaunde propuso en La crisis presente ${ }^{60}$. Delinear una estrategia paliativa para frenar el declive moral de la sociedad peruana (fortaleciendo las limitaciones formales e informales) se reflejaría positivamente en el carácter de las interacciones sociales y, por tanto, en la lucha contra la corrupción ${ }^{61}$. La crisis, para el joven Belaunde, tenía su origen en el desquiciamiento de la moralidad pública, un hecho con repercusiones en la transmisión y configuración de la cultura ${ }^{62}$. Más aún, la destrucción de la capacidad

apoyo de los hijos del autor, Antonio y Martín Belaunde Moreyra. Sería la sexta y fue dada a la imprenta bajo el título La crisis presente (1994). Es la que se cita en este trabajo.

58 La cúpula partidista esencialmente generacional del PND no impidió que Riva Agüero y los suyos intentasen descentralizar su iniciativa. Sobre este punto véase Planas, 1996: 171189.

59 Belaunde, 1994: 113.

60 Harrison, 1985: 14. Desde otro marco ideológico, Lipset, 1987: 344-345, también reconoce la importancia de los valores en la configuración de las creencias al interior de una clase social concreta.

${ }^{61}$ El enfoque que Belaunde planteó hace casi un siglo es de una actualidad sorprendente. Las prácticas corruptas en el ejercicio de la función pública se mantienen como uno de los más graves problemas de los países en desarrollo. Véase Huntington, 1997: 377, cuando afirma que «corruption obviously exists in all societies, but it is also obviously more common in some societies than in others and more common at some times in the evolution of a society than at other times. Impressionistic evidence suggest that its extent correlates reasonably well with rapid social and economic modernization». En el mismo sentido, Levi y Nelken, 1996. Heydenheimer et al., 1997. López de la Osa y Campo Sánchez, 2000. Villoria, 2006.

62 Boyd y Richerson, 1985: 2. 
económica estaba condicionada por una dimensión moral que edificaba pautas conductuales basadas en un capital social determinado. Con el fin de analizar el marco institucional en el que se plasmaba dicha crisis, el discurso de 1914 fue esquematizado en tres grandes capítulos: «La crisis económica», «La crisis de la clase media» y «La crisis de la clase dirigente».

Belaunde sostuvo que el porvenir risueño que esbozó Francisco García Calderón en su obra El Perú contemporáneo (1907) se había desvanecido por completo. La deuda alarmante del Estado, la falta de consolidación de las instituciones, la destrucción de los mecanismos electorales, la imposibilidad de alcanzar acuerdos en el Parlamento por la exacerbación de la dialéctica partidista, el híper presidencialismo, la división de la clase dirigente, el empobrecimiento y la dependencia burocrática de la clase media, las primeras agitaciones de las masas populares, la corrupción y la desorientación en la política internacional eran los signos visibles de una democracia de baja intensidad caracterizada por la debilidad sistémica debido, esencialmente, a la corrupción de los valores y la cultura del desarraigo. Por eso, para Belaunde, «esta crisis económica es política y moral al mismo tiempo [...] todo fenómeno político envuelve una cuestión moral» ${ }^{63}$. La política se presentaba, de esta manera, como la materialización de un enfrentamiento entre diversas cosmovisiones portadoras de valores distintos. En tal sentido, Belaunde, desde su reformismo liberal, reivindicaba la importancia de instituciones informales en la construcción del orden social. Detrás de cada complejo de limitaciones estructurales que ralentizaba el desarrollo armónico de la sociedad peruana, Belaunde intuyó la existencia de patrones de comportamiento basados en valores comunes que servían de elementos de cohesión. Por tanto, de la misma forma en que el marco institucional influye en el rendimiento político y económico, el marco valorativo determina la evolución y el cambio de los entornos institucionales ${ }^{64}$.

Así, por ejemplo, la crisis financiera del Estado peruano fruto del endeudamiento progresivo, confluyó en el aumento exponencial de los gastos públicos, signos, según Belaunde, «de derroche y mala administración», propios de una cultura cívica decoratista e imitativa ${ }^{65}$. Para sanear la economía y

63 Belaunde, 1994: 114-115. Aunque hablando de los Estados Unidos, Lipset, 2000: 386, señala que existe una tendencia social a identificar la decadencia moral como causa y efecto de la crisis económica.

${ }^{64}$ Harrison y Huntington, 2010: XXXII-XXXIV.

65 Véase, Macías Picavea, 1979: 269-274. Por su parte, Belaunde, 1987: 43-72, enumera los vicios del Perú: incoherencia, rencores, ironía, ignorancia, decoratismo, pobreza sentimental. 
evitar la bancarrota se tornaba imperativo establecer una nueva estrategia fiscal, una suerte de «régimen dietético», empleando para ello la discrecionalidad de las instituciones políticas (Belaunde, 1994: 116-117). Por otro lado, la crisis del poder ejecutivo estaba ligada, según el arielismo, al absolutismo presidencial. Siguiendo a García Calderón, Belaunde sostuvo que, a pesar del intento de la república aristocrática de consolidar las estructuras republicanas, el cesarismo de sedimentos burocráticos no había sido eliminado del todo. Este caudillismo populista se concentró, formalmente, en la institución presidencial, una institución deformada por la omnipotencia práctica del poder ejecutivo, excesivamente dependiente de la voluntad del presidente y de los pactos y coaliciones que sostenían al gobierno en su mandato.

El carácter monárquico del híper presidencialismo peruano generaba consecuencias negativas en el orden financiero y en el político. En el plano financiero, el híper presidencialismo provocó la destrucción del presupuesto público debido a la amplia discrecionalidad que tenía el presidente para utilizar las finanzas del Estado con el fin de repartir sinecuras y fortalecer la coalición de poder. Lo que en La crisis presente Belaunde denominó «la influencia del dinero» se tradujo, finalmente, en la captura del Estado por parte del caudillismo, configurando un cesarismo burocrático institucionalizado, capaz de prolongar la debilidad sistémica del gabinete, ya que los ministros, limitados de hecho por las prerrogativas presidenciales, hacían gala de una «inclinación dimisionaria» como única forma de presión. Así, su utilidad política, circunscrita al legalismo del refrendo constitucional, estaba opacada por la relevancia pública del presidente, a quien Belaunde equiparó a un virrey «sin juicio de residencia» ${ }^{66}$. Las soluciones aparentes, lógicas y armoniosas de la estructura legal eran, en el fondo, imaginarias, espejismos formales de compleja aplicación. En el escenario real, el presidente instrumentalizaba a sus colaboradores apoyando su acción política en tradiciones y reglas levemente «juridificadas», en virtud de un sistema estructurado jerárquicamente, propio de esa tendencia autoritaria que caracteriza la historia de la humanidad $^{67}$. La crítica al excesivo poder de la institución presidencial no se tradujo en la total oposición de Belaunde al presidencialismo. Por el contrario, lo

66 Belaunde 1994: 119-120. El paralelo belaundiano entre el virrey y el presidente es uno de los más conocidos del pensamiento político peruano. Los mecanismos de control del virreinato eran ampliamente superiores a los del presidencialismo novecentista peruano: «el presidente de la república es un virrey sin monarca, sin Consejo de Indias, sin oidores y sin juicio de residencia». El problema, de alguna manera, se ha prolongado hasta la actualidad. Véase Belaunde 1994: 120-121.

67 Somit y Peterson, 1997. 
juzgó necesario siempre y cuando sus prerrogativas fuesen controladas por un sistema de equilibrios institucionales ejercido por aristocracias locales y regionales, resaltando el papel conciliador del Parlamento y la importancia de una clase media fiscalizadora, únicos grupos sociales capaces de resistir la excesiva personalización de la institución presidencial y la inestabilidad de un pueblo (aún no se hablaba de ciudadanía) proclive a la demagogia y el populismo.

La acentuación del personalismo ejecutivo estaba correlacionada, según Belaunde, con la crisis política del Parlamento, la crisis económica de la clase media y la crisis moral de la clase dirigente. El sectarismo político que profundizaba los clivajes partidistas y estructurales se tradujo en el fortalecimiento de un «espíritu de partido» que generó mayorías prepotentes, lo cuál, por fuerza, provocó la inversión «inmoral y absurda de funciones» que caracterizaba al poder ejecutivo del novecientos ${ }^{68}$. Semejante tendencia provocó que la institución presidencial legislase merced a su influencia en las cámaras y que éstas, a su vez, administrasen en el ámbito ejecutivo por su poder discrecional en los nombramientos políticos. Este poder discrecional impulsaba de manera negativa el predominio de los intereses locales en el proceso técnico de configuración presupuestaria, generando desorden, corrupción y evasión fiscal. Un Parlamento burocratizado, con excesivo poder decisorio en el ámbito estatal-administrativo $\mathrm{y}$, a la vez, condicionado por la acción política del híper-presidencialismo, frenaba la renovación institucional y se convertía, de tal forma, en un actor clave para sellar el pacto de las elites local-provinciales con el gobierno de turno. Todo ello, sumado a la ausencia de una oposición orgánico-partidista y a la ambición ministerial de los parlamentarios, generaba escenarios de confrontación por el control de la agenda política. Así, el Parlamento, antes de profundizar su rol fiscalizador promoviendo la rendición de cuentas en el sistema político, centraba sus esfuerzos en el diseño de una estrategia de poder y en la cooptación de nuevos espacios de influencia, en función a sus intereses institucionales. Esta aspiración, más realista -aunque negativa e incluso perniciosa- consolidaba la ineficacia del control parlamentario, sesgado por los incentivos individuales de permanencia en el poder ${ }^{69}$.

En tal sentido, la explicación de la crisis parlamentaria, para Belaunde, se enmarcaba en un plano diádico subjetivo-objetivo. La tesis subjetiva atribuía todos los males institucionales a la «inmoralidad» de los hombres y señalaba

68 Belaunde, 1994: 126.

69 Un rasgo propio del oficio de la política. Véase, sobre el particular, Alcántara, 2012: 165-166. 
«el remoto remedio de la educación $»^{70}$. A pesar de reconocer su validez, para Belaunde el diagnóstico es incompleto y por tanto ineficaz. En contra, la argumentación objetiva no excluye la causa de la inmoralidad pero avanza al resaltar la influencia de esa inmoralidad en el mundo concreto de las instituciones. Por eso, la crisis «es compleja, tiene sus causas morales y causas institucionales o legales. No sólo los hombres son malos, las instituciones y organismos están mal constituidos $\rangle^{71}$. Bajo tal marco analítico, la crisis no sólo es de valores, también es de diseño, de public management, de enforcement institucional. En suma, también ha de tenerse en cuenta la ingeniería del Estado.

Por eso, Belaunde propuso en La crisis presente una serie de remedios técnicos a la crisis parlamentaria, especialmente, el equilibrio en la distribución de los escaños y el principio de proporción entre electores y representantes. También abogó por una mejor correlación entre ambos actores sosteniendo que el pacto entre el gobierno y el provincialismo electoral (las fuerzas locales) debilitaba la institucionalidad parlamentaria, fomentando la continuidad de una cultura clientelista, de fuertes patronazgos económicos. La aspiración arielista de control democrático y eficacia en la separación de poderes se plasmó en el intento -finalmente abortado- de crear un sistema electoral basado en la realidad nacional y no en los privilegios seculares del gamonalismo, cuya expresión política, el semi-feudalismo provincial (a manera de dirigismo partitocrático) distorsionaba el balance del poder central ${ }^{72}$. La desproporción electoral, consolidada de manera sistémica, provocaba que la presidencia se encontrase sumamente condicionada en su política regional por las provincias, en detrimento de las ciudades, polos de modernización y desarrollo. De esta manera, la institución presidencial, con el fin de imponer políticas nacionales de manera unilateral, pactaba con las provincias, legitimando de facto las redes de corrupción y sus espacios de poder. A cambio de mantener diversos privilegios formales, perennizando el status quo social y económico, recibía de ellas (de los barones locales) el apoyo para llevar a cabo la agenda del gobierno en el ámbito nacional.

De hecho, el provincialismo fue duramente denunciado en La crisis presente como sinónimo de inmovilismo y marco de abuso para la explotación de la población indígena, a manera de encarnación del «funesto interés lo-

\footnotetext{
70 Belaunde, 1994: 128.

71 Ibidem: 129.

72 Por eso Belaunde sostuvo que: «Vive este feudalismo pero ya sin religión, sin poesía y sin gloria». Véase, García Belaunde y Gonzales, 2007: 95.
} 
cal» ${ }^{73}$. Llevar a cabo una reforma institucional que liquidase el localismo arcaizante implicaba fortalecer la estructura estatal y dotar de recursos a los departamentos frente a las provincias, con el fin de provocar la ruptura de la alianza entre la institución presidencial y los poderes locales, restableciendo un gobierno bajo el control de los poderes públicos. Así, frente al cese del pacto entre el híper presidencialismo y las provincias, las tendencias absorbentes del centralismo menguarían, y el localismo estaría condenado al declive, favoreciendo a las ciudades en su función de inclusión social. De esta manera, Lima, la capital, se vería incapaz de evitar el fortalecimiento de ciudades y departamentos, los cuáles pasarían a desempeñar el papel de entidades «robustas, de cultura intensa y de desarrollo de opinión pública» ${ }^{74}$. La descentralización del poder garantizaba un control difuso, una mejor rendición de cuentas y el retorno a un estado de equilibrio de poder.

Para Belaunde, no sólo el Parlamento se presentaba como una fuerza política de resistencia al absolutismo. También «la masa popular» aunque esta sólo actuase «en los movimientos revolucionarios» ${ }^{75}$. Así, ante el carácter eventual de la intervención popular en la política del novecientos -un extremo que mutaría con el leguiísmo- y frente al secuestro del Parlamento por parte del poder ejecutivo, la creciente clase media y la clase dirigente tradicional se convertían, en el marco de este análisis conservador, en las fuerzas llamadas a ejercer el control de las instituciones. Sin embargo, la función fiscalizadora de las clases con mayor acceso a la educación -en plena consonancia con el ideal rodosiano- colisionaba dialécticamente con la agenda política del gobierno. La clase media, burocratizada, carecía de independencia económica y, por tanto, era incapaz de una acción política eficaz. El arielismo identificó a la clase media con los burócratas que dependían del Estado, un grupo obligado a someterse a la disciplina de la administración pública sosteniendo su política general ${ }^{76}$. La tendencia a eliminar clases y procesos de control promoviendo la interacción directa del presidente con las masas se consolidaría, finalmente, con el advenimiento del «Oncenio» de Augusto B. Leguía, un populismo inclusivo que se aprovechó de la desestructuración del poder ${ }^{77}$.

73 Belaunde, 1994: 146.

74 Ibidem: 151.

75 Ibidem: 152.

76 Este extremo ha mudado por completo. Ahora se trata de una clase emprendedora que interviene en múltiples actividades económicas. Véase, sobre este punto, Arellano y Burgos, 2010. Córdova, 2010; 2011.

77 La tendencia se prolongaría a lo largo del siglo XX en un proceso político en el que se alternan democracias precarias y autoritarismos competitivos, ante la ausencia de partidos 
Para evitar la debilidad de los mecanismos de representación, Belaunde, en La crisis presente, identificó las bases económicas de la clase media, dedicada, fundamentalmente, a la pequeña industria, la propiedad reducida y el comercio a escala regional. El Perú, por entonces, no era un país industrial. Los arielistas, para explicar este fenómeno, se aferraban al argumento biológico-educativo, tan propio del positivismo novecentista: el criollo está adormecido por el clima y debilitado por la educación. Belaunde sostuvo que por tal razón la clase dirigente se conformaba con el intelectualismo decorativo, postergando la necesidad de una formación nacional para el trabajo libre, la empresa y el desarrollo técnico. La solución consistía en proyectar, desde el Estado, una educación de sesgo tecno-pragmático, cuyos objetivos girasen en torno a la formación profesional de la clase media, porque de sus canteras era posible nutrir un partido de ideología liberal, objetivo político del arielismo ${ }^{78}$.

Para que tal escenario fuera posible, era preciso llevar a cabo un diseño institucional capaz de transformar los institutos superiores en centros de educación tecnocrática, dotados de los avances pedagógicos y tecnológicos necesarios para un pragmatismo focalizado, cuya finalidad era el desarrollo armónico del país. Así, la mejora en la calidad educativa técnica de una clase media con menos dependencia de la burocracia estatal, unida a la supresión de la base provincial política y la implementación de un sistema departamental electoral se presentaban como factores necesarios para consolidar la influencia política de la clase media, un colectivo esencial en el proyecto partidista del arielismo. En este sentido, La crisis presente fue un discurso dirigido a las elites sobre un estamento, aunque ausente en el foro, de creciente importancia en la sociedad latina: la clase media. De hecho, la falta de independencia económica y la excesiva tendencia burocrática convertían a la clase media en un grupo de riesgo para la práctica de actividades corruptas. La precariedad económica que la caracterizaba -su lema, para Belaunde, era «techo y despensa»- tornaban imprescindibles las políticas que buscaban desarrollar su aptitud para la «lucha económica», fomentando la capacidad emprendedora que se precisaba para fortalecer su autonomía frente al Estado ${ }^{79}$.

Sin embargo, según Belaunde, el factor fundamental para explicar la crisis social no era otro que el declive moral de la clase dirigente, una elite que, a pesar de la aparente paradoja nominal «muy pocas veces ha dirigido la marcha

fuertes (party strenght) y la fragilidad del Estado. Véase Dargent, 2009. Tanaka, 2010. Sobre el Oncenio, véase Leguía Olivera, 2007. Reaño García, 2009.

78 De allí que García Calderón sostuviese que el Perú se salvaría bajo toneladas de polvo de biblioteca. Véase García Calderón, 2003: 53-57.

79 Belaunde, 1994: 154-155. 
del Estado», fracasando en su empeño de controlar el desequilibrio, la corrupción y la ilegalidad, por su tendencia a plegarse a todos los regímenes o dividirse en la confrontación dialéctica hasta la anarquía. Así: «Esta clase dirigente ha preferido colaborar usufructuando a dirigir; ha huido de las grandes ambiciones con sus responsabilidades y peligros, y de los grandes renunciamientos con sus sacrificios; ha buscado el camino fácil y ha llegado al poder cuando el sendero se encontraba despejado; en otras circunstancias, ha preferido las posiciones secundarias u holgadas ${ }^{80}$.

Para remediar la postración moral de la elite, un factor que la inclinaba a colaborar con los cesarismos de turno, Belaunde propuso desarrollar un proyecto educativo dirigido a reforzar el ethos de la clase dirigente. El sesgo mercantilista de la clase dirigente había fracasado, debilitando al país de manera notable. Según Belaunde, la elite en el poder vivía «...en el constante desdén de los valores morales». El reduccionismo economicista provocó que la agenda política estuviese condicionada por la maximización de beneficios materiales para los diversos grupos que detentaban el poder. Ante tal hipertrofia de cuño utilitario, trabajo y moralidad se presentaban como la «síntesis salvadora». De esta manera, frente a la crisis económica de la clase media, La crisis presente postula la creación de empleos libres del yugo estatal fruto del emprendimiento. Y frente a la crisis moral de la clase dirigente, la respuesta de Belaunde es de tipo cultural-valorativo, ya que insiste en la transformación de las instituciones (formales e informales) mediante una pedagogía axiológica, apelando a una ética vinculada al public management. Así, «...trabajo y moralidad, sentimiento de la acción, filosofía pragmática, tal debe ser nuestra orientación» ${ }^{81}$.

La síntesis de vitalismo axiológico y pragmatismo desarrollista se plasmó en un ambicioso programa de reforma educativa - esencialmente universitariaorientado a otorgarle a las clases media y popular la aptitud para el desarrollo económico, sin descuidar «la sugestión de un ideal político y moral superior ${ }^{82}$. Belaunde rechazó el reduccionismo geográfico y el determinismo del factor racial, oponiéndose tanto al Estado predador como al ausentismo de las elites (elite defection). En cierta forma, propuso un retorno al ideal revolucio-

80 Ibidem: 156, sostuvo que la clase dirigente aprobó todos los grandes errores en función al rédito económico. Así, hipotecando la calidad de la democracia al inmediatismo de la agenda económica, su lema, derivado de un excesivo afán crematístico, fue la perversión de aquél de Carlos V: «plus ultra», «más allá, el maximum (sic) posible».

81 Ibidem: 157. En la edición de 1940, Belaunde puntualiza en una nota que: «no podríamos hoy repetir esta adhesión a la filosofía pragmática. La acción por la acción ha sido reemplazada en nuestro espíritu por la acción para el ideal o para el deber».

82 Belaunde, 1994: 161. 
nario americano, un moralismo bolivariano tamizado de realismo nacionalista $^{83}$. Tal simbiosis política buscó frenar la creciente debilidad del Perú del novecientos, una tendencia reflejada en la liquidación del proceso reformista iniciado tras la guerra con Chile, cuya consecuencia manifiesta recayó en la pérdida de relevancia geopolítica del Perú en el plano regional.

Al vincular idealismo y ética al desarrollo material y económico, La crisis presente transformó el discurso positivista del novecientos en uno más complejo, pluridimensional, de raíz culturalista, rescatando la necesidad de incorporar a la clase media y promover liderazgos inclusivos capaces de generar modelos eficaces de arquitectura democrática. Así, la síntesis de realismo social e idealismo valorativo se presentó como la base de las reformas institucionales que precisaba el país ante la delicada coyuntura económica que sirvió de preludio al leguiísmo. Por eso, La crisis presente apuesta por un régimen híbrido que recoja la complejidad de la realidad peruana ${ }^{84}$. Este realismo no se agotaba en el análisis formalista y, por tanto, rechazó de plano el anatopismo, la cultura imitativa que evadía las variables peculiares de cada país, postergándolas en beneficio de soluciones generalistas ${ }^{85}$. El ausentismo generaba, a la postre, utopías disociativas que ralentizaban la integración nacional. En concreto, la evasión institucional - «somos desarraigados» diría Belaunde- influía de manera negativa en la calidad de la democracia ${ }^{86}$.

El diseño institucional propugnado por Belaunde estaba vinculado a la defensa de una democracia posibilista. Si el absolutismo fue limitado por la oligarquía y ella, a su vez, estuvo condicionada por el control de la clase media, era imprescindible, para completar la estructura de equilibrio social en un marco de state-building, dotar al pueblo de organización partidista y educación de calidad. El sistema político novecentista privilegiaba el liderazgo personalista que pactaba con las oligarquías. Belaunde denunció este pacto que debilitaba el objetivo de construir un Estado impersonal fundado en el principio de imparcialidad, instrumento clave para el desarrollo ${ }^{87}$. Esta actitud inclusiva no llegó hasta la defensa de la democracia total, pero sí configuró

83 A Bolívar dedicó una de sus obras más importantes, de prestigio internacional: Bolívar y el pensamiento político de la revolución hispanoamericana (1959).

${ }_{84}$ Ciertamente, no en el sentido peyorativo, ampliamente difundido, que le otorga al concepto Diamond, 2002. Se trataría de un régimen híbrido por la fusión de elementos formales e informales. La carga positiva o negativa gravitaba en función a su adscripción a una ética concreta, por ejemplo, la de la democracia delegativa.

${ }^{85}$ Los arielistas eran reformistas al estilo del regeneracionismo español. Conocían la distinción entre el país formal y el país real. Véase Arroyo, 577-578 (Madrid, 1998): 299-312.

86 Belaunde, 1994: 164.

87 Rothstein, 2011: 22. 
un avance significativo en lo que respecta al papel decisivo en la esfera pública de masas históricamente postergadas por elites reacias a compartir el poder ${ }^{88}$.

Con todo, el marco analítico de Belaunde destacó la importancia de las elites para la construcción de una democracia eficiente. Elites capaces de implantar en la realidad instituciones diseñadas para el fortalecimiento del Estado de Derecho que respetasen las particularidades del escenario político local. Elites, además, dotadas no sólo de herramientas técnicas para el gobierno sino también de valores capaces de generar un clima moral contrario a la instrumentalización del poder por móviles particulares. Sin dejar de sostener la pertinencia de «minorías superiores» formadas en la Universidad, Belaunde se inclinó por un control recíproco y multidimensional entre la clase media (que debe organizarse y convertirse en fuerza política), las masas populares (educadas en una cultura de desarrollo integral) y una elite capaz de evitar que el gobierno degenere en una oligarquía acostumbrada a pactar con el cesarismo burocratizado, agente de corrupción ${ }^{89}$. Tal equilibrio forjado por un sistema de check and balances se presentaba, para Belaunde, como una condición necesaria para la mejora de la calidad de la política peruana (la regeneración), un proceso al que se dedicaría de manera infructuosa, influyendo de manera notable en la configuración de los partidos de centro-derecha en el Perú ${ }^{90}$.

\section{A MANERA DE CONCLUSIÓN: «QUeREMOS PATRIA»}

Si la corrupción es, como algunos politólogos sugieren, una institución informal ${ }^{11}$, entonces es preciso que las estrategias diseñadas para combatirla también contemplen probables soluciones que surjan del propio plano cultural-valorativo. La excesiva juridificación de los problemas sociales dificulta la transformación cultural en un lapso corto de tiempo porque el decisionismo legal genera rupturas institucionales en todos los niveles. La crisis presente señala un antes y un después en el análisis político peruano prefigurando numerosas discusiones teórico-prácticas sobre el diseño del entramado insti-

88 Belaunde, 1994: 164. De allí, tal vez, el creciente desprestigio de la clase política, que con el tiempo no hace sino profundizarse. Véase al respecto Little y Posada-Carbó, 1996: 7.

89 Nótese que Belaunde asume que la política es dialéctica, oposición, y que la función de control permite aspirar a una síntesis eficaz mediante la aplicación de un liderazgo valorativo que rescate el ideal a manera de «voluntad creadora». Véase Belaunde, 1994: 166.

90 Planas, 1996.

91 Levitsky y Way, 2010: 28. 
tucional, teniendo en cuenta que, en un marco de development performance, el desempeño del Perú ha sido, tal y como lo profetizaron los arielistas, inferior al de otros países latinos ${ }^{92}$. Existe un continuum entre la postura de Belaunde y las aproximaciones positivistas que le preceden. Sin embargo, $L a$ crisis presente sintetiza diversas teorías reemplazando la mirada esencialmente organicista por una postura superadora de asimetrías en virtud del enfoque de matriz ético-social. Así, Belaunde señala la importancia de una acción política basada en valores capaces de activar el cambio institucional generando espacios concretos de eficiencia, lo que repercute en la construcción paulatina de aquello que O'Donnell llamó, con acierto, el «Estado fuerte» ${ }^{93}$.

Este derrotero mixto de reformas institucionales y moral development configurará, con el tiempo, la característica esencial del pensamiento belaundiano, ya vislumbrado en la frase final de su discurso, teñida de idealismo nacionalista: « $i$ Queremos patria! $»^{94}$. Por ahora, sin embargo, la Arcadia arielista continúa siendo esquiva. En efecto, el patriotismo funcional de Belaunde no se agota en la construcción de un Estado basado en la institucionalidad demo-liberal. Al rescatar la importancia de la realidad nacional (el enfoque peruanista) como factor esencial de análisis -e identificar la desviación corrupta como una variable correlacionada con el vitalismo axiológico- Belaunde establece las bases de una aproximación cognitiva multidisciplinar, que completa el diseño de las instituciones con el estudio de los valores que las informan. Sin embargo, en La crisis presente Belaunde no llegó a concretar del todo ese ideal moral que, según él, debía inspirar la regeneración política de la realidad peruana. Años después, tras su retorno al cristianismo, propuso como «única solución» a la crisis institucional cuasi-endémica la aplicación de los principios del programa social-cristiano, resaltando su carácter supra-partidista y la presunta eficacia de su marco analítico en la construcción de instituciones impersonales capaces de equilibrar las distorsiones del poder ${ }^{95}$.

Sin dejar de lado la micropolítica y otras miradas rigurosas y técnicas con soporte empírico, es preciso reconocer la especial importancia del enfoque valorativo en el ámbito de la lucha contra la corrupción. La ingeniería institucional presta soluciones momentáneas a problemas de fondo, pero es inconsistente cuando aspira a transformar instituciones informales arraigadas en la

\footnotetext{
92 McClintock, 1999: 349.

93 O’Donnell, 1997: 339. Altuve, 2006 señala, desde el otro extremo del espectro ideológico, la necesidad de una democracia fuerte.

94 Belaunde, 1994: 167.

95 Belaunde, 1967b: 1075.
} 
esfera pública con resonancia en los regímenes políticos ${ }^{96}$. El escepticismo weberiano con respecto al análisis normativo perjudica una aproximación integral a los problemas políticos de nuestro tiempo ${ }^{97}$. En tal sentido, reexaminar el derrotero que postula el fortalecimiento de la ética pública como un factor beneficioso para la correcta aplicación del Estado de Derecho, se apoya en la noción -hoy ampliamente extendida- de que el buen gobierno está estrechamente vinculado a la aplicación de una accountability eficiente por parte de personas que interactúan en virtud de códigos valorativos.

Llegados a este punto, vale la pena recalcar que, ante la proliferación de instituciones inadecuadas -porque bajo esta categoría han de encuadrarse las que se aferran a una asepsia formalista e irreal-, los incentivos no funcionarán o, lo que es peor, generarán resultados perversos ${ }^{98}$. Sin una ética común que legitime el sistema institucional retroalimentando una cultura de la legalidad, cualquier afán reformista marchará incompleto $\mathrm{y}$, por ende, condenado al fracaso. La democracia es un proceso inacabado, de interacciones complejas ${ }^{99}$. De alguna manera encarna el reformismo permanente al que aspira la mayor parte del espectro político. De allí surge la premisa del fortalecimiento institucional como respuesta holística sujeta a la dimensión temporal. La pulsión por el poder sólo puede controlarse si se edifica un entramado ético-institucional que encauce el decisionismo jurídico y el voluntarismo utópico en clave política. Naturalmente, no puede existir un buen gobierno sin una buena sociedad ${ }^{100}$ y el largo proceso de pedagogía cívica que propuso Belaunde hace casi cien años sólo era -sólo es- comprensible si se tiene en cuenta este encuadre normativo.

He aquí la actualidad del análisis arielista belaundiano. Cuando la democracia prescinde de esta base mínima valorativa, ralentiza su desarrollo y debilita las bases de la convivencia social. Belaunde, un novecentista condicionado por su zeitgeist, se basó en esta premisa axiomática para defender la necesidad de una síntesis política de instituciones y valores como remedio a la grave crisis que atravesaba el Perú, una crisis que se reflejaba, particularmente, en el carácter expansivo de una corrupción rampante que, sin llegar a

96 Lauth, 2000. Collins, 13/3 (Baltimore, 2002); 35/2 (New York, 2003). Helmke y Levitsky, 2006; 2011.

97 Beetham, 1999: 8.

98 Rodrik, 2007: 153. Para una postura que reconoce la ambivalencia de los incentivos frente a formas tradicionales de hacer política, véase Dargent, 2005: 398.

99 Beetham, 1999: 69.

100 Villoria, 2006: 39. 
ser sistémica ${ }^{101}$, influyó de manera decisiva en la percepción que la ciudadanía tenía de la elite. Una corrupción que se mantiene y que demanda, como acertadamente ha señalado Manuel Villoria, «un compromiso colectivo y un ejercicio continuo de las virtudes ciudadanas» ${ }^{102}$. Pocos años después, con la ampliación del demos, el aprismo de Víctor Raúl Haya de la Torre y el socialismo de José Carlos Mariátegui, supieron capitalizar la ruptura entre la elite y las masas, transformando la estructura de partidos y liquidando los residuos de la República Aristocrática. Testigo lejano de este proceso, solitario impugnador desterrado por la dictadura leguiísta, Belaunde regresó al Perú tras diez años de exilio tan sólo para contemplar cómo su mundo se había derrumbado. Con todo, supo influir de manera individual en la reconfiguración del centro político, promoviendo el social-cristianismo, y evitando, en palabras de Oaekshott, «la deshonra de la extinción» ${ }^{103}$.

\section{BIBLIOGRAFÍA}

AA.VV., Libro Jubilar de Víctor Andrés Beñaunde, Lima, 1963.

Ades, Alberto y Di Tella, Rafael, "The New Economics of Corruption: a Survey and some New Results", Political Studies 45 (1997): 496-515.

Alcántara, Manuel, ¿Instituciones o máquinas ideológicas? Origen, programa y organización de los partidos latinoamericanos, Barcelona, Institut de Ciènces Politiques i Socials, 2004.

Alcántara, Manuel, El oficio de político, Madrid, Tecnos, 2012.

Almond, Gabriel y Verba, Sidney, The civic culture: political attitudes and democracy in five nations, Little, Brown and Company, 1965.

Altuve, La democracia fuerte y otras herejías políticas, Lima, Editorial Reino, 2006.

Arellano, Rolando y Burgos, David, Ciudad de los Reyes, de los Chávez, de los Quispe, Lima, Planeta, 2010.

Arroyo Reyes, Carlos, "Entre el regeneracionismo y el Volksgeist. El joven Belaunde y la Generación del 98", Cuadernos Hispanoamericanos 577-578 (Madrid, 1998): 299-312.

101 Para profundizar en torno a la diferencia entre corrupción «venal» y «sistémica», véase Wallis, 2006: 25.

102 Villoria, 2006: 22.

103 Oaekshott, 2007: 47. 
Bardhan, Pranab, “Corruption and Development: A Review of Issues", Journal of Economic Literature, 35/3 (Pittsburgh, 1997): 1320-1346.

Basadre, Jorge, Historia de la República del Perú: 1822-1933, Quinto periodo: la República Aristocrática, tomo XI, Lima, Editorial Universitaria, 1970.

Beetham, David, Democracy and Human Rigths, Cambridge, Polity Press, 1999.

Belaunde, Víctor Andrés, Trayectoria y destino I, Lima, Ediciones Ediventas S.A., $1967 \mathrm{a}$.

Belaunde, Víctor Andrés, Trayectoria y destino II, Lima, Ediciones Ediventas S.A., $1967 b$.

Boyd, Robert y Richerson, Peter, Culture and the Evolutionary Process, Chicago, University Press of Chicago, 1985.

Belaunde, Víctor Andrés, Obras completas I-VI, Lima, Editorial Lumen, 1987.

Belaunde, Víctor Andrés, La crisis presente (1914-1939), Lima, Luis Alfredo Ediciones, 1994.

Belaunde, Martín y García Belaunde, Domingo, Víctor Andrés Belaunde. Epistolario político con Manuel Prado e Ismael Bielich, Lima, Pontificia Universidad Católica del Perú, Instituto Riva Agüero, 2009.

Brinkerhoff, Derick, "Assessing Political Will for Anticorruption Efforts: An Analytic Framework", Public Administration and Development 20 (2000): 239-252.

Choi, Jay Pil y Thum, Marcel, "Corruption and the Shadow Economy", International Economic Review, 46/3 (2005): 817-836.

Collier, Paul, El club de la miseria. Qué falla en los países más pobres del mundo, Madrid, Turner, 2008.

Collins, Kathleen, "Clans, Pacts and Politics in Central Asia", Journal of Democracy, 13/3 (Baltimore, 2002): 137-152.

Collins, Kathleen, “The Political Role of Clans in Central Asia”, Comparative Politics, 35/2 (Nueva York, 2003): 171-190.

Córdoba, Daniel, Los nuevos héroes peruanos. Lecciones de vida de emprendedores que derrotaron la pobreza, Lima, Planeta, 2010.

Córdoba, Daniel, Los nuevos héroes peruanos 2. Lecciones de vida de emprendedores que derrotaron la pobreza, Lima, Planeta, 2011.

Cossío del Pomar, Felipe, Haya de la Torre: el indoamericano, Lima, Editorial Nuevo Día, 1946.

Dargent, Eduardo, "Juzgando a los señores: reflexiones sobre los procesos anticorrupción en el Perú”, Felipe Portocarrero (ed.), El pacto infame. Estudios sobre la corrupción en el Perú, Lima, Red para el desarrollo de las Ciencias Sociales en el Perú, 2005: 377-402. 
Dargent, Eduardo, Demócratas precarios. Elites y debilidad democrática en el Perú y América Latina, Lima, Instituto de Estudios Peruanos, 2009.

De la Riva Agüero, José, Obras completas I-XVII, Lima, Pontificia Universidad Católica del Perú, 1962-2000.

Diamond, Larry, Political Culture and Democracy in Developing Countries, Boulder, Lynne Rienner Publishers, 1994.

Diamond, Larry, “Thinking about Hybrid Regimes", Journal of Democracy, 13/2 (Baltimore, 2002): 21-35.

Diamond, Larry, The Spirit of Democracy: The Struggle to build Free Societies throughout the World, Nueva York, Times Books-Henry Holt and Co., 2008.

Doig, Alan y McIvor, Stephanie, "Corruption and its control in the developmental context an analysis and selective review of the literature", Third World Quarterly, 20/3 (Londres, 1999): 657-676.

Eguiguren, Luis Antonio, Alma Mater. Orígenes de la Universidad de San Marcos (1551-1579), Lima, Talleres Gráficos Torres Aguirre, 1939.

Fritzen, Scott, "Beyond 'political will': How institutional context shapes the implementation of anti-corruption policies", Policy \& Society, 24/3 (Singapur, 2006): 79-96.

García, Alan, Contra el temor económico: creer en el Perú, Lima, Planeta, 2011.

Garcia Belaunde, Domingo y Gonzales, Osmar, Víctor Andrés Belaunde, Peruanidad, contorno y confín. Textos esenciales, Lima, Fondo Editorial del Congreso del Perú, 2007.

García Calderón, Francisco, José de la Riva Agüero. Recuerdos, Lima, Imprenta Santa María, 1949.

García Calderón, Francisco, América Latina y el Perú del 900. Antología de textos, Lima, Universidad Nacional Mayor de San Marcos, 2003.

García Morales, Alfonso, Literatura y pensamiento hispánico de fin de siglo, Clarín y Rodó, Sevilla, Secretariado de Publicaciones de la Universidad, 1992.

Gascó Contell, Emilio, José Enrique Rodó: estudio y antología, Madrid, Compañía Bibliográfica Española, D.L., 1970.

Gonzales Prada, Manuel, Páginas libres; Horas de lucha, Caracas, Biblioteca Ayacucho, 1976.

Harrison, Lawrence, El sub desarrollo está en la mente: el caso latinoamericano, Buenos Aires, Rei, 1985.

Harrison, Lawrence y Huntington, Samuel (eds.), Culture Matters. How Values Shape Human Progress, Nueva York, Basic Books, 2010.

Heidenheimer, Arnold et al. (eds.), Political Corruption, New Brunswick-Londres, Transactions Publishers, 1997. 
Heywood, Paul, Political Corruption, Oxford, Blackwell Publishers, 1997.

Hill, Kim, "Democratization and Corruption: Systematic Evidence from the American States", American Politics Research, 31 (2003): 613-631.

Huntington, Samuel, "Modernization and corruption", Arnold J. Heidenheimer, Michael Johnston, Victor T. Levine (eds.), Political Corruption, New Brunswick-Londres, Transaction Publishers, 1997.

Jain, Arvind K. (ed.), The Political Economy of Corruption, Londres-Nueva York, Routledge, 2001.

Johnston, Michael, Public-Sector Corruption (4 vols.), Londres, Sage UK, 2010.

Kaufmann, Daniel, “Corruption: The Facts”, Foreign Policy, 107 (Washington, 1997): 114-131.

Klaiber, Jeffrey, La Iglesia en el Perú, Lima, Fondo Editorial de la Pontificia Universidad Católica del Perú, 1996.

Klitgaard, Robert, Tropical Gangsters. One Man's Experience with Development and Decadence in deepest Africa, Londres, Tauris, 1991.

Klitgaard, Robert y Light, Paul, High-performance government: Structure, Leadership, incentives, Santa Mónica, RAND, 2005.

Lauth, Hans-Joachim, "Informal Institutions and Democracy", Democratization, 7/4 (Londres, 2000): 21-50.

Leguía Olivera, Enriqueta, Lima 1919-1930, la Lima de Leguía, Lima, Fondo Editorial de la Universidad de San Marcos, 2007.

Levi, Michael y Nelken, David, The Corruption of Politics and the Politics of Corruption, Oxford-Cambridge, Blackwell Publishers, 1996.

Levitsky, Steven y Helmke, Gretchen, Informal Institutions and Democracy. Lessons from Latin America, Baltimore, The John Hopkins University Press, 2006.

Levitsky, Steven y Way, Lucan, Competitive Authoritarianism. Hybrid Regimes After the Cold War, Cambridge, Cambridge University Press, 2010.

Levitsky, Steven y Roberts, Kenneth, The Resurgence of the Latin American Left, Baltimore, The John Hopkins University Press, 2011.

Lipset, Seymour Martin, El hombre político: las bases sociales de la política, Madrid, Tecnos, 1987.

Lipset, Seymour Martin, El excepcionalismo norteamericano: una espada de dos filos, México, Fondo de Cultura Económica, 2000.

Lipset, Samuel Martin y Lenz, Gabriel Salman, "Corruption, Culture and Markets", Lawrence E. Harrison y Samuel P. Huntington (eds.), Culture Matters. How Values Can Shape Human Progress, Nueva York, Basic Books, 2000: 112-124. 
Little, Walter y Posada-Carbó, Eduardo (eds.), Political Corruption in Europe and Latin America, Londres-Nueva York, MacMillan Press LTD, 1996.

Loayza, Luis, Sobre el 900, Lima, Mosca Azul editores, 1990.

López de la Osa, José Ramón y Campo Sánchez, Carlos, Crisis de valores y de normas a finales del siglo XX, Madrid, PS, 2000.

Macías Picavea, Ricardo, El problema nacional, Madrid, Instituto de Estudios de Administración local, 1979.

Maíz, Claudio, De París a Salamanca: trayectorias de la modernidad en Hispanoamérica. Aportes para el estudio del novecientos, Salamanca, Ediciones de la Universidad de Salamanca, 2004.

Mariátegui, José Carlos, Siete ensayos de interpretación de la realidad peruana, Lima, Biblioteca Amauta, 1995.

Mariátegui, José Carlos, Invitación a la vida heroica. Textos esenciales, Lima, Fondo Editorial del Congreso del Perú, 2005.

Matos Mar, José, Desborde popular y crisis del Estado. Veinte años después, Lima, Fondo Editorial del Congreso del Perú, 2004.

Melé, Domènec y Castellà, Josep M., El desarrollo humano integral. Comentarios interdisciplinares a la encíclica Caritas in Veritate de Benedicto XVI, Barcelona, Editorial ITER, 2010.

Meléndez, Carlos y Vergara, Alberto, La iniciación de la política. El Perú político en perspectiva comparada, Lima, Pontificia Universidad Católica, 2010.

McClintock, Cynthia, "Peru: Precarious Regimes, Authoritarian and Democratic", Larry Diamond, Jonathan Hartlyn, Juan Linz y Seymour Martin Lipset (eds.), Democracy in Developing Countries: Latin America, Boulder, Lynne Rienner, 1999: 308-366.

Moynihan, Daniel Patrick, Pandaemonium: ethnicity in international politics, Oxford, Oxford University Press, 1993.

Neira, Hugo, Hacia la tercera mitad. Perú XVI-XX. Ensayos de relectura herética, Lima, Siklos, 2005.

Noonan, John T., Bribes, Berkeley, University of California Press, 1987.

North, Douglas C., Institutions, Institutional Change and Economic Performance, Cambridge, Cambridge University Press, 1990.

North, Douglas C., Wallis, John Joseph y Weingast, Barry R., Violence and social orders: a conceptual framework for interpreting recorded human history, Cambridge, Cambridge University Press, 2009.

O’Donnell, Guillermo, Contrapuntos: ensayos escogidos sobre autoritarismo y democratización, Buenos Aires, Paidós, 1997. 
Oakeshott, Michael, La actitud conservadora, Asmara, Sequitur, 2007.

Orrego Penagos, Juan Luis, "Víctor Andrés Belaunde”, Grandes forjadores del Perú, Lima, Lexus Editores, 2001.

Pacheco Vélez, César, Ensayos de simpatía. Sobre ideas y generaciones en el Perú del siglo XX, Lima, Universidad del Pacífico, 1993.

Pareja Paz Soldán, José, El maestro Belaunde, Lima, Editorial Universitaria, 1968.

Planas, Pedro, Los orígenes del APRA. El joven Haya, Lima, OKURA, 1986.

Planas, Pedro, Biografía del movimiento social-cristiano en el Perú (1926-1956), Lima, Konrad Adenauer Stiftunf-Gráfica San Pablo, 1996.

Prieto Celi, Federico, Así se hizo el Perú. Crónica política de 1939 a 2009, Lima, Grupo Editorial Norma-Escuela de Dirección de la Universidad de Piura, 2010.

Putnam, Robert, Bowling alone: the collapse and revival of American community, Nueva York, Simon \& Schuster, 2000.

Putnam, Robert, Democracies in flux: the evolution of social capital in contemporary society, Oxford, Oxford University Press, 2002.

Putnam, Robert, El declive del capital social: un estudio internacional sobre las sociedades y el sentido comunitario, Barcelona, Galaxia Gutenberg/Círculo de lectores, 2003.

Putnam, Robert, American Grace: how religion divides and unites us, Nueva York, Simon \& Schuster, 2010.

Quiroz, Alfonso, Corrupt Circles. A History of Unbound Graft in Peru, Washington D.C./Baltimore, Woodrow Wilson Center Press, 2008.

Quintanilla, Pablo, "Del espejo al caleidoscopio: aparición y desarrollo de la filosofía en el Perú", Areté Revista de Filosofía, XVI/1 (Lima, 2004): 43-79.

Reaño García, José, Historia del Leguiísmo, sus hombres y sus obras, Lima, Fondo Editorial de la Universidad de San Marcos, 2009.

Rey y Cabieses, Amadeo-Martín, "Linaje y vida de Víctor Andrés Belaunde. Un peruano universal”, Junta Sabatina de Especialidades Históricas, 4 (Buenos Aires, 2003): 73-111.

Rodó, José Enrique, Ariel. Motivos de Proteo, Caracas, Biblioteca Ayacucho, 1976.

Rodó, José Enrique, Obras completas, Madrid, Aguilar, 1967.

Rodrik, Dani, One economics, many recipes: Globalization, institutions, and economic growth, Princeton/New Jersey, Princeton University Press, 2007.

Rose-Ackerman, Susan, La corrupción y los gobiernos. Causas, consecuencias y reforma, Madrid, Siglo XXI de España Editores, 2001. 
Rothstein, Bo, The Quality of Government. Corruption, Social Trust and Inequality in International Perspective, Chicago/Londres, The University of Chicago Press, 2011.

Saint Upery, Marc, "¿Hay patria para todos? Ambivalencia de lo público y emergencia plebeya en los nuevos gobiernos progresistas", Iconos. Revista de Ciencias Sociales, 032, (Quito, septiembre 2008): 75-87.

Sánchez, Luis Alberto, Balance y liquidación del novecientos. ¿Tuvimos maestros en nuestra América?, Lima, Universidad Nacional Mayor de San Marcos, 1968.

Sánchez, Luis Alberto, Conservador no, reaccionario sí, Lima, Mosca Azul editores, 1985.

Schleifer, Andrei y Vishny, Robert, "Corruption", Quarterly Journal of Economics, 108/3 (Oxford, 1993): 599-617.

Somit, Albert y Peterson, Steven, Darwinism, Dominance, and Democracy: the biological bases of authoritarianism, Westport, Praeger, 1997.

Sowell, Thomas, Conflict of Visions, Nueva York, Morrow, 1987.

Tanaka, Martín, "La estructura de oportunidad política de la corrupción en el Perú: algunas hipótesis de trabajo", Felipe Portocarrero (ed.), El pacto infame. Estudios sobre la corrupción en el Perú, Lima, Red para el desarrollo de las Ciencias Sociales en el Perú, 2005.

Tanaka, Martín (ed.), El Estado, viejo desconocido. Visiones del Estado en el Perú, Lima, Instituto de Estudios Peruanos, 2010.

Torrano, Hugo, Rodó, acción y libertad: Restauración de su imagen, Montevideo, Barreiro y Ramos, 1973.

Treisman, Daniel, "The causes of corruption: a cross-national study", Journal of Public Economics, 76 (2000): 399-457.

Vanucci, Alberto, "The Controversial Legacy of 'Mani Pulite': A Critical Analysis of Italian Corruption and Anti-Corruption Policies", Bulletin of Italian Politics, 1/2 (2009): 233-264.

Vargas Haya, Héctor, Perú: 184 años de corrupción e impunidad, Lima, Alberto Soler Peña/Antonio de la Puente Uceda Editores, 2005.

Villoria Mendieta, Manuel. La corrupción política, Madrid, Síntesis, 2006.

Von Alemann, Ulrich, "The unknown depths of political theory: The case for a multidimensional concept of corruption", Crime, Law \& Social Change 42, (2004): 25-34.

Wallis, John Joseph, "The Concept of Systematic Corruption in American History", Edward L. Glaeser y Claudia Goldin (eds.), Corruption and Reform: Lessons from America's Economic History, Chicago, University of Chicago Press, 2006: 23-62. 
Weyland, Kurt, "The Politics of corruption in Latin America", Journal of Democracy, 9/2 (1998): 108-121.

Weyland, Kurt, Learning from Foreign Models in Latin American Policy Reform, Washington D.C./Baltimore/Londres, Woodrow Wilson Center Press-The John Hopkins University Press, 2004.

Williamson, Oliver E., The Economic Institutions of Capitalism: firm, markets, relational contracting, Nueva York, Free Press, 1985.

Zaldumbide, Gonzalo, Cuatro clásicos americanos: Rodó, Montalvo, fray Gaspar de Villaroel, P.J.B. Aguirre, Madrid, Cultura Hispánica, 1951.

Fecha de recepción: 27 de septiembre de 2012.

Fecha de aceptación: 25 de noviembre de 2012.

\section{Corruption and Regeneration. Víctor Andrés Belaunde and "La Crisis Presente}

Victor Andrés Belaunde, one of the most relevant thinkers of Latin American Arielism, held that it was necessary to combine institutional design with a regeneration of values, as a solution to the political crisis that Peru was experiencing. Thus, the combination of institutional design and axiological or ethical vitalism created a holistic approach that introduced into the public debate a vision of integral development in which the fight against corruption and institutional problems could be addressed, in a complementary way, from an ethical perspective. This dimension served to strengthen the construction of an inclusive State, one of the political objectives of the Arielian generation.

Key Words: Corruption; regeneration; Victor Andrés Belaunde; arielismo; La crisis presente. 
